Extended Abstract

\title{
Makers and Users
}

\author{
Alexandre Borovik ${ }^{1}$ \\ ${ }^{1}$ University of Manchester, School of Mathematics, Manchester M13 9PL, United Kingdom \\ E-Mail: alexandre@,borovik.net
}

Accepted:

\section{Introduction}

I suggest a simple thought experiment. Science fiction books occasionally mention an imaginary device: a replicator. It consists of two boxes; you put an object in a box, close the lid, and instantly get its undistinguishable fully functional copy in the second box. In particular, a replicator can replicate smaller replicators.

Now imagine the economy based on replicators. It needs two groups of producers: a very small group of engineers who build and maintain the biggest replicator and a very diverse, but still small, group of artisans, designers, and scientists who produce a single original prototype of each object. This hypothetical economy also needs service sector, mostly waste disposal.

Next, try, if you can, imagine a sustainable, stable, equal, and democratic model of education that supports this lopsided economy.

But this apocalyptic future is already upon us - in the information sector of economy, where computers act as replicators of information. Mathematics, due to its special role in the information technology, is the most affected part of human culture. The new patterns of division of labour split mathematics for makers from mathematics for users and trigger a crisis of mathematics education. The latter increasingly focuses on mathematics for users and undermines itself because sustainable reproduction of mathematics requires teachers educated as makers.

\section{The ultimate replicating machines}

I borrowed the title of this section from a chapter in my book [1]. I argue there that the essence of mathematics is its precise replicability which imitates the stability of laws of the physical universe, that 
A mathematical theorem needs to be proved only once - and then used for centuries. An algorithm needs to be developed only once - and then it can serve, as the Google Ranking Algorithm does, as a kingpin of a global information system.

In previous historic epochs, every use of a mathematical result required participation of humans, who had to understand what they were doing and therefore had to be mathematically educated; the criterion of understanding was the ability to reproduce the proof. Nowadays, mathematics is used mostly by computers, not by people, and used in an instantly replicable way.

This creates a completely different socio-economic environment for mathematics.

\section{Division of labour}

As I argue in my paper [3], the history of human civilisation is the history of division of labour. By the start of the 21 st century, the ever deepening division of labour has reached a unique point when $99 \%$ of people have not even the vaguest idea about the workings of $99 \%$ of technology in their immediate surrounding. This transformation is deeper than the Great Industrial Revolution of $18^{\text {th }}$ and $19^{\text {th }}$ centuries, and its social consequences have a chance to be more dramatic.

Mathematics and mathematics education are the proverbial canaries in the mine, they are more sensitive to this technological change. It costs to make ("replicate") a smartphone, it costs to write an app for smartphone, but the per unit cost of mathematics encoded and hardwired within the phone converges to zero.

There are more mobile phones in the world now than toothbrushes. But the mathematics built into mobile communication systems is beyond the understanding of most universities' graduates. This creates a paradox: mathematics is used in everyday life millions of times more intensively than 50 or even 10 years ago - but remains invisible.

Meanwhile, mathematical results and concepts involved in practical applications are much deeper and more abstract and difficult than ever before. The cutting edge of mathematics research moves further away from the stagnating mathematics education. From the point of view of an aspiring $\mathrm{PhD}$ student, mathematics looks like New York in the Capek Brothers' book A Long Cat Tale [4] (and notice that Karel Capek was the man who coined the word "robot"):

And New York - well, houses there are so tall that they can't even finish building them. Before the bricklayers and tilers climb up them on their ladders, it is noon, so they eat their lunches and start climbing down again to be in their beds by bedtime. And so it goes on day after day.

Investment cycles and research-and-development cycles in many modern industries are just two years long. On the other hand, proper mathematics education still takes at least 15 years from the age of 5 to the age of 20 - or even 20 years if postgraduate studies are needed.

As I argue in [3], mathematics education is being undermined by this tension between the ever deepening specialisation of labour and ever increasing length of specialised training required for jobs at the increasingly sharp cutting edge of technology.

If banks and insurance companies were interested in having numerate customers, we would witness the golden age of school mathematics - fully funded, enjoying cross-party political support, promoted 
and popularised by the best advertising companies in all forms of mass and social media. But they are not; banks and insurance companies need numerate workforce - and even more so they need innumerate customers.

25 years ago in the West, the benchmark of arithmetic competence at the consumer level was the ability to balance a chequebook. Nowadays, bank customers can instantly get full information about the state of their accounts from an app on a mobile phone - together with timely and tailored to individual circumstances advice on the range of available financial products. As Anna Sfard [5] put it,

It is enough to take a critical look at our own lives to realize that we do not, in fact, need much mathematics in our everyday lives.

In short, the present model of "mathematics education for all" is unsustainable and, not surprisingly, first cracks have started to appear. On the other hand, the reproduction cycle of mathematics

primary school - high school - university - teacher training - a teacher's return to school

is 20 years long, and it is not clear at all whether the current model of education could be smoothly and peacefully replaced by the new one, aimed at in-depth mathematics education of a much smaller stratum of people. Assessments of this situation from the opposite ends of the political spectrum are instructive:

Failure in achieving a meaningful mathematics education is not a malfunction which could be solved through better research and a proper crew, but is endemic in capitalist schooling. (Alexandre Pais [6])

While there is an upside limit to the average intellectual capabilities of population, there is no upper limit to the complexity of technology. ... With ... an apparently inbred upper limit to human IQ, are we destined to have an ever smaller share of our workforce staff our ever more sophisticated hightech equipment and software? (Alan Greenspan [7])

\section{Mathematics education}

When previously meaningful social activities (and social institutions supporting them) loose their economic purpose, they either collapse or transform themselves into a complex of rituals, "cargo cult," in the words of Richard Feynman. In the "cargo cult" environment, everything goes. This is why we see the explosive growths in the number of various approaches and methods tried at school - because there are no objective bottom-line criteria to distinguish between them.

Here, I want to touch on a popular myth: that the same computer technology that kills demand for mathematics will save mathematics education.

First of all, we have to distinguish between education and training. As a famous saying goes,

"For those of you with daughters, would you rather have them take sex education or sex training?" 
This witticism makes it clear what is expected from education as opposed to training: the former should give a student ability to make informed and responsible decisions.

This is the old class divide that tears many education systems apart: education is for people who are expected to make decisions and give orders; training is for ones who take orders.

However it is increasingly accepted that modern mathematics education is not even training of workforce for future employment (this model of education is so $20^{\text {th }}$ century), it is filtering of workforce by means of mathematical tests - even if no mathematics is needed at the actual workplace. Computers could be very efficient tools for training students to pass tests - I do not dispute that. However, although the skill of passing a mathematics test remains personally important, it becomes increasingly redundant at the scale of the economy as a whole. An exam at the end of the course should test students' ability to perform certain tasks - but in case of school and college mathematics, these tasks now are much better performed by computers - see a detailed discussion of that in [3]. Then what is the aim of training? The ability to imitate robots? Are students' skills assessed are of any economic (or "real life") value if computers can pass the tests in an instant and with better scores than humans?

\section{Makers and Users}

So far I was looking at the emerging new social environment of mathematics. Now a few words on consequences for mathematics itself.

The new patterns of division of labour split mathematics for makers from mathematics for users. How $t$ describe the two? The replicability of mathematics mirrors the stability of laws of the physical universe, which is captured by the apocryphal formula:

\section{Mathematics is the language of contracts with Nature which Nature accepts as binding.}

It is dangerous to replace, in this formulation, "Nature" by "Computer" - but it appears that this increasingly frequently happens in practice. Therefore, in my understanding, Mathematics for Makers is mathematics that cannot be entrusted to computers, mathematics for those whose duty is writing contracts with Nature, in the process inventing new mathematics and new ways to apply mathematics. In terms of the "universal replicator" simile from the Introduction, these are people who produce the originals for subsequent replication.

The mainstream mathematics education increasingly focuses on mathematics for users. But sustainable reproduction of mathematics requires teachers educated as makers - on that point, I refer the reader to my paper [8].

\section{Conclusions}

The expansionist model of mathematics education is dying because the technological changes in the wider economy lead to the shift of demand for mathematically competent workers: smaller numbers 
are needed, but much better educated. Compression cracks are more destructive and less predictable than expansion gaps - for the obvious reason: where should the excessive mass go? Potential social consequences bring to mind the apocryphal curse

May you live in interesting times;

It looks as if interesting times are already upon us. But I do not takes sides in the increasingly politicised debate. In my view, most policies in mathematics education can be divided in two categories:

- rearranging chairs on the deck of Titanic (the preferred option of the political Right);

- helping disadvantaged passengers to get better chairs on the deck of Titanic (the preferred option of the political Left).

My role is different, I am with my fellow teachers in the famous band that continues to play regardless. Not the first violin, of course; I am in the back row, with a tuba: "Boop, boop, boop, boop." I am a mathematician; I will play to the end.

\section{Disclaimer}

The author writes in his personal capacity; his views do not necessarily represent the position of his employer or any other person, corporation, organisation or institution.

\section{References and Notes}

1. Borovik, A. V. Mathematics under the Microscope: Notes on Cognitive Aspects of Mathematical Practice, American Mathematical Society, Providence, USA, 2010; pp. 217 - 245.

2. Stewart, I. Does God Play Dice? The Mathematics of Chaos. Penguin, London, UK, 1990.

3. Borovik, A. V. Calling a spade a spade: Mathematics in the new pattern of division of labour, to appear. A pdf file: http://goo.gl/TT6ncO

4. Capek, K.; Capek, J. A Long Cat Tale, Albatros, Prague, The Czech Republic, 1996; p. 44.

5. Sfard, A. Why Mathematics? What Mathematics? In The Best Writings on Mathematics, Pitici M., Ed.; Princeton University Press, Princeton, USA, 2013; pp. 130-142.

6. Pais, A. An ideology critique of the use-value of mathematics, Educ. Stud. Math., 2013, vol. 84, pp. $15-34$.

7. Greenspan, A. The Map and the Territory: Risk, Human Nature and the Future of Forecasting, Allen Lane, USA, 2013.

8. Borovik, A. V. Didactic transformation in mathematics teaching, http://www.academia.edu/189739/Didactic transformation in mathematics teaching

(C) 2015 by Alexandre Borovik; licensee MDPI and ISIS. This abstract is distributed under the terms and conditions of the Creative Commons Attribution license. 